\title{
CPTED Measures in a Gated Residential Area
}

\author{
Siti Rasidah Md Sakip ${ }^{1}$, Aldrin Abdullah² \\ ${ }^{1}$ Faculty of Architecture, Planning \& Surveying, Universiti Teknologi MARA, Perak, Malaysia \\ ${ }^{2}$ School of Housing, Building \& Planning, Universiti Sains Malaysia, Pulau Pinang, Malaysia \\ ieda02fiq@yahoo.com
}

\begin{abstract}
The observation approach is often used as a measurement tool for examining the Crime Prevention Through Environmental Design (CPTED) elements in residential areas. However, this method of evaluation, which is merely based on observations are seen to be inadequate. This is due to the fact that CPTED is closely tied to community-based relationships, which is not easily measured through short period observations. This study reports the findings of a pilot study which evalutes CPTED measures based on face-to-face questionnaire survey. The study was conducted in a gated residential areas located at Bukit Jambul in Penang, Malaysia. The results found that the measures of CPTED using Cronbach Alpha (a) index for all components of CPTED were 0.6 and above suggesting that the measures are reliable and valid. The study revealed that CPTED is correlated to Sense of Community but not to Fear of Crime.
\end{abstract}

Keywords: CPTED, crime, fear of crime, sense of community, gated residential area.

eISSN 2514-751X @ 2017 The Authors. Published for AMER ABRA by e-International Publishing House, Ltd., UK.. This is an open access article under the CC BY-NC-ND license (http://creativecommons.org/licenses/by-ncnd/4.0/). Peer-review under responsibility of AMER (Association of Malaysian Environment-Behaviour Researchers), ABRA (Association of Behavioural Researchers on Asians) and cE-Bs (Centre for EnvironmentBehaviour Studies), Faculty of Architecture, Planning \& Surveying, Universiti Teknologi MARA, Malaysia.

https://doi.org/10.21834/aje-bs.v2i4.208 


\subsection{Introduction}

There are various approaches in understanding crime prevention: (i) from the aspects of the legal system or the enforcement of the policing and monitoring system (Dantzker and Robinson, 2002), (ii) social approach (Welsh and Hoshi, 2002, Syarmila Hany, 2008, Simons, 2002, Bennet et al., 2006), (iii) offender approach (Cozens et al., 2005) and (iv) physical environmental approach (Brantingham and Brantingham, 2005, Newman, 1972, Blakely and Synder, 1997, Jacobs, 1961). Designers such as architects and planners often focus on reducing crime by engaging the physical environmental aproach. This approach is based on the understanding that the physical environment can be modified through planning and design in order to reduce the opportunities for crime (Nasar \& Fisher, 1993). As discovered by Lamya Rostami and Ali Madanipour (2006), elements such as physical layout, housing typology and the outlook of the surrounding environment directly influence crime. Therefore, it can be deduced that poor physical environmental design contributes towards higher crime (Anastasia and John, 2007).

The Crime Prevention Through Environmental Design (CPTED) approach emphasizes on the elimination of opportunities for the occurences of crime through planning and design (Jeffery, 1974). The modification of the physical environmental elements is seen to be able to reduce the possibility of crime. The only notable work that measures CPTED was conducted by Minnery and Lim (2005). As the dimensions of CPTED have not been rigously evaluated, the main objective of this pilot study is to identify the reliability and validity of CPTED measures and to examine its relationship components in fostering sense of community and reducing anxiety towards crime.

\subsection{Literature Review}

Crime is a global issue. Each act of crime is different in terms of the desired incentive or its etiological process. It involves three environmental factors that occur simultaneously, namely: (i) the targeted victim either an individual, a group or property, (ii) the offender with the motivation to commit the offence, and (iii) the presence of the opportunity to commit crime (Brantingham and Brantingham, 1993).

In Malaysia, the crime rate is seen to be increasing annually for the past 32 years. This increase is mainly attributed to crimes against the property as opposed to violent crimes ( $P$. Sundramoorthy, 2008). Among the seven types of property crime in Malaysia, home breakins during night time register the highest number of occurrences in a period of seven years compared to other forms of property crime (PDRM, 2008). This situation is influenced by the environmental factors, specifically night time conditions that accord a sense of ease to the criminals to act against their intended targets (Birkbeck and Lafree, 1993). Based on the types of property crime, the crimes that specifically involve residential areas are crimes that entail house break-ins. Moreover, crimes that normally embroil victims during the incidence of crime are home burglaries and break-ins which also impart a traumatic and frightening 
experience to the victims and in some cases cause the loss of life (Birkbeck and Lafree, 1993). It is estimated that as much as 78 percent of crime occurrences that involve victims during the incidences are attributed to home break-ins (Robertshaw and A. Mtani, 2001).

In terms of crime prevention methods, it cannot be denied that good relationship between residential community members is vital in ensuring crime rate reduction. This relationship refers to the social interaction within the local community members. A good social interaction can be defined as the capability and ability of the community members to gather together and congregate regularly (Villarreal and Silva, 2006). This contributes towards the collective efficacy among the community members based on civic activities within the social control. As an indirect effect, it gives emphasis on the involvement capacity of the residents to act collectively in developing themselves or overcoming local problems (Ferguson and Mindel, 2007). The development of this social connection in turn will be able to reduce the occurrences of crimes such as home break-ins, vehicle theft as well as burglaries in residential areas (Villarreal and Silva, 2006). In the Malaysian context, this is supported by a study at Taman Dato' Harun, Petaling Jaya, Malaysia. It was found that there was a theft reduction of $5.6 \%$ when the local neighbourhood watch scheme known as "Rukun Tetangga" was introduced (Hafazah dan Siti Mareenah, 2010).

The success of CPTED is based on five main components: (i) territoriality, (ii) surveillance, (iii) access control, (iv) maintenance and target hardening and, (v) support activity. Territoriality can be defined as a concept that reinforces the notion of proprietary concern and a 'sense of ownership' by legitimate users of space, thereby reducing opportunities for offending by discouraging illegitimate users. Surveillance is based on the physical design which enables the capacity to promote informal or natural surveillance opportunities for residents and their agents, thus making surveillance a part of capable guardianship. If offenders perceive that they can be observed, they may be less likely to offend, given the increased potential for intervention, apprehension and prosecution. Access control reduces the opportunities for crime by denying access to potential targets as well as creating a heightened perception of risk. Maintenance and target hardening promote a positive image and to routinely maintain the built environment to ensure that the physical environment continues to function effectively and transmits positive signals to all users. Installing elements of target hardening increases the efforts that offenders must expend in the commission of a crime and the last component, support activity, can be defined as the use of design and signage to encourage intended patterns of usage in public spaces.

Nevertheless, the measurement of all these components of CPTED in research is still very limited. This limitation is noted by Minnery and Lim (2005) as well as Hedayati (2009). The majority of previous research focused mainly on a single component of CPTED alone, for example, (i) territoriality (Crowe and Zahm, 1994; Perkins et al., 1993; Aldrin, A., 1999), (ii) surveillance (Jacobs, 1961; Newman, 1973; Perkins, et al.,1993; Nes and Rueb, 2009), (iii) access control (Brantingham and Brantingham, 1993; Crowe and Zahm, 1994; Shu, 1999; Cozens, 2002; Shu., 2009) and, (iv) maintenance and target hardening (Newman, 1972; Liebermann and Kruger, 2004). Researchers that have measured all five of the 
CPTED components in their research are Minnery and Lim (2005) and Hedayati (2009), but there were differences in terms of the CPTED components and the selection of residential areas. Minnery and Lim (2005) conducted an evaluation of four CPTED components, namely, (i) access control, (ii) surveillance, (iii) support activity and (iv) target hardening in two low and medium cost housing areas in Gold Coast, Australia. Hedayati (2009) on the other hand, undertook a research based on four CPTED components, namely, (i) surveillance (ii) access control (iii) territoriality and, (iv) maintenance in three different types of residences involving terrace, detached and semi-detached houses in a residential area located in Penang, Malaysia. Both these research utilized a common approach, namely, observation.

The measurement of CPTED components based on observations alone is found to be lacking and deficient. Measurements on attitude, actions, belief, responsibilities and residents' scrutiny are equally as important. This is because the concept of CPTED requires social interaction in determining its effectiveness towards crime prevention (Cozens et al., 2005). Therefore, this pilot study conducted measurements on the four CPTED components of (i) territoriality, (ii) surveillance, (iii) maintenance and target hardening and, (iv) support activity by incorporating a questionnaire survey form. The area identified for this research involved a gated residential area as according to Blakely and Synder (1997), as close to 70 percent of American residents have moved to gated residential areas due to security concerns against the threat of crime.

\subsection{Methodology}

Fifty respondents were randomly selected from residential areas located in Burmah Road at Bukit Jambul, Penang, Malaysia to become samples for the study. The respondents involved in this pilot survey were head of households or the main income earner. This is vital as the study involves the attitude as well as the sense of responsibility towards the respondents' residential area. A face-to-face interview was administered to ensure that the respondents fully understood the questions that were forwarded to them. The survey was conducted within a one-week period, beginning from 9 am until $5 \mathrm{pm}$ each day. Respondents that were not available during normal working hours were interviewed during weekends.

The measures of the CPTED were based on the comprehension of each CPTED component. This is explained as follows:

- Territoriality: involves a sense of responsibility and the ability to identify strangers within their spaces. Subsequently, among the items used in the questionnaire were items such as; (i) "I am able to recognize strangers that pass by in front of my house", and (ii) "I always make sure that the surrounding compound of my house is always clean to let it be known that this is my area".

- Surveillance: the ability of the residents to monitor their surrounding area. Some 
of the items used were; (i) "I immediately inspect the external surroundings whenever I overhear loud or suspicious noises" and (ii) "I can clearly see the external surrounding areas even when I am inside my house".

- Maintaiance and target hardening: The state of the house environment that portrays a good image as well as the installation of security systems. Among the items used were; (i) "I immediately repair the doors and windows of my house when they become defective", (ii) "I have installed alarms in my house for security purposes".

- Support activity: programmes or activities that involve the local community and are able to create a secure and safe space. Among the items that were used are; (i) "Every week, community programmes such as aerobic workouts, competitions involving children are frequently held in this residential area" and (ii) "Whenever I am out exercising.

All of these CPTED components were measured using a 5 point Likert Scale: 1 strongly agree, 2 - agree, 3 - no opinion, 4 - disagree and 5 - strongly disagree. In addition, the study also measured fear of crime (FOC) and sense of community (SOC) utilizing a similar 5-point Likert Scale.

\subsection{Results And Discussions}

This pilot study involved more female respondents $(56 \%)$ compared to male respondents $(44 \%)$ with a majority of the respondents being in the 20 s - 40s age groups $(74 \%)$. The respondents were from the three main races in Malaysia, namely Malays (48\%), Chinese $(36 \%)$ and Indians (12\%). Almost all of the respondents (92\%) involved in this survey have never been victims of crime in the past. However, the percentage of respondents who have heard or known about crime cases occurring in the area of study was relatively high (66\%). A big majority of the types of crime that have occurred in the study area are house breakins, recording $96.2 \%$, involving theft of money, jewellery, electrical appliances and equipment as well as home furniture. Only $3.8 \%$ of the crimes were those concerning vehicle theft. From the aspects of validity and reliability, the items for each Crime Prevention Through Environmental Design (CPTED), Fear of Crime (FOC) and Sense of Community (SOC) dimensions were measured using the Cronbach alpha (a) analysis. An item-to-scale value of 0.3 was used as the minimum value for a unidimensional scale (de Vaus, 1986), while the scale was considered reliable if the alpha value was 0.6 and above, based on the criteria suggested by De Vellis (1991). The results of the analysis demonstrated that all five items under the territoriality dimension were valid as the a value $=$ 0.72 . This was found to be similar for the surveillance dimension which involved three items and recorded an a value $=0.78$. For the maintenance and target hardening dimensions, from all the 7 items listed and used, three items were omitted as they recorded a corrected 
item-to-total correlation value of below 0.3 , while the total alpha value of the 7 items was $a=0.49$. Those three items were; (i) "I have installed a closed circuit television system at home for security monitoring", (ii) "When the external paint of my house fades, I immediately repaint it" and (iii) "I immediately repair the doors and windows of my house when they become defective". After these three items were eliminated and analysis was redone, the resulting a value $=0.66$. This illustrates that the remaining 4 items are valid in measuring the maintenance and target hardening dimensions. For the support activity dimension which had four items, the Cronbach alpha (a) analysis conducted resulted in an $a$ value $=0.59$. There were two items under this dimension that had to be omitted in order to obtain an a value of above 0.6. The two items that were excluded were; (i) "Every week, community programmes such as aerobic workouts, competitions involving children are frequently held in this residential area" and (ii) "I frequently participate in the community programmes organized in this residential area". This meant that only 2 items were valid measures of support activity $(a=0.63)$. As the dimensions for each CPTED component were comprised of items of dissimilar numbers, it was necessary necessary to standardize the scores in order to ensure homogeneity in terms of percentages for each dimension using the criteria suggested by de Vaus (1986). Each dimension was allotted a score value of 25 percent, thus totaling 100 percent when all four CPTED dimensions are combined. This in turn enables a more uniform level for the purposes of correlation analysis for each variable.

The measurement for fear of crime (FOC) involved three dimensions namely anxiety towards the physical and social environment, and indirect crime victimization. The results showed that 1 of the 9 items had a corrected item-to-total correlation value of 0.15 . Consequently, this item was omitted and the resulting reanalysis recorded an a value $=$ 0.77 . The item that was removed was "I believe that good rapport with my neighbours will reduce fear of crime". Therefore, 8 out of the 9 items were used to measure FOC.

For the measurement of sense of community (SOC), there are four main dimensions, namely; (i) community participation, (ii) influence and beliefs, (iii) need emphasis and (iv) emotional sharing. Each dimension has three items, hence a total of 12 items. The analysis reveals that 4 out of the 12 items show a corrected item-to-total correlation value of below 0.3 , while the total alpha value for the 12 items was 0.74 . Re-analysis after these 4 items were eliminated resulted in a value of 0.79 . The remaining 8 items are valid measures of SOC. The four items that were removed are; (i) "I feel this residential area is suitable for occupancy", (ii) "I enjoy being a part of the community in this residential area", (iii) "I am concerned with the remarks of my neighbours regarding all my actions" and (iv) "I do not have any influence over what happens within this residential area".

The correlation analysis between CPTED and the Fear of Crime (FOC) as well as the Sense of Community (SOC) levels was conducted using the Spearman's rho. The results in Table 1 indicate a significant weak correlation between CPTED and SOC $(r=0.39, p<.01)$. Meanwhile, the results for the Spearman correlation test analysis between CPTED and FOC was found to be non-significant $(r=0.142, p>.01)$. This demonstrates that there is no 
correlation between CPTED and FOC.

Table 1: Correlation Table between CPTED, FOC and SOC

\begin{tabular}{|c|c|c|c|c|c|}
\hline & & & CPTED & FOC & $\mathrm{SOC}$ \\
\hline \multirow[t]{3}{*}{ Spearman's rho } & CPTED & $\begin{array}{c}\text { Correlation Coefticient } \\
\text { Sig. (2-taled }) \\
\text { N }\end{array}$ & $\begin{array}{c}1.000 \\
50\end{array}$ & $\begin{array}{l}.142 \\
.326 \\
50\end{array}$ & $\begin{array}{l}369^{+4} \\
.005 \\
50\end{array}$ \\
\hline & FOC & $\begin{array}{l}\text { Correlation Coetticient } \\
\text { Sig. (2-taled) } \\
\text { N }\end{array}$ & $\begin{array}{l}.142 \\
.326 \\
50\end{array}$ & $\begin{array}{c}1.000 \\
50\end{array}$ & $\begin{array}{l}.220 \\
.124 \\
50\end{array}$ \\
\hline & $s o c$ & $\begin{array}{c}\text { Correlation Coefticient } \\
\text { Sig. }(2-t a l e d) \\
\text { N }\end{array}$ & $\begin{array}{l}.389 * \\
.005 \\
50\end{array}$ & $\begin{array}{l}.220 \\
.124 \\
50\end{array}$ & $\begin{array}{l}1.000 \\
50\end{array}$ \\
\hline
\end{tabular}

". Correlation is signincant at the 01 leves (2-taled)

The correlation between Fear of Crime (FOC) and gender, on the other hand, is significant. This is based on the results of the Mann-Whitney $U$ test analysis, which shows that there is a significant difference in terms of feelings of anxiety between the genders. The Mann-Whitney $U$ test demonstrates that $(z=-3.87, p=.000)$ it is significant at the $p<.01$ level. The mean rank value for the female sex (32.55) is above that of the male sex (16.52) suggesting that the female gender feels more worried when compared to their male counterparts. The correlation analysis between Sense of Community (SOC) and the different genders, meanwhile is found to be non-significant. The results of the data analysis using the Mann-Whitney $\mathrm{U}$ test records $(z=-.678, p=.498)$ is non-significance at 0.5 level. The mean rank score for the female gender (26.73) is just slight more than the male gender (23.93) which points out that gender does not have a correlation with community relationship ties.

As with the discoveries by previous researchers that there is a significant correlation between Fear of Crime (FOC) and victimization, the findings of this pilot study have come to a similar conclusion. The analysis of the data using the Mann-Whitney $U$ test $(z=-.1975, p$ $=.048)$ shows the correlation between FOC and victimization is significant $(p<0.5)$. The mean rank score for 'Yes' - have been a victim of crime (39.25) is higher than that of 'No' have never been a victim of crime (24.30) which in turn illustrates that a person who has been a victim of crime is naturally more worried than those who have never been a victim of previous crime.

\subsection{Conclusions}

This pilot study is intended to gauge the measures of CPTED before the actual study is conducted. A pilot study also functions as a means to identify potential problems that may crop up in the actual study as well as to evaluate the suitability of the study questions (Piaw, 2009). In the case of this pilot study that was conducted, several problems were 
identified regarding the sentence structure as well as the use of the 5 point Likert scale. In terms of the problems with the sentence structure, it was discovered that in the "Anxiety Level Towards Crime" measurement section, some items contained words that did not representing the actual intention of the core inquiry. Therefore, these items were rephrased by replacing the word "fear" with "worry" as well as the repetitious use of the word "influencing" for each of the items. This is in order to give a more clear emphasis on the actual meaning of each item.

The Support Activity dimension in the components of CPTED will also be eliminated from the actual study. This is due to the fact that the item-to-item correlations were weak $(0.298$ and 0.297 respectively). Both these items were intended to find out about the implementation of community programmes that were organized as well as the participation from the community members. Through observation, it was found that the weakness of these items were because they were vague in terms of measuring the subject matter.

In general, it was discovered that the use of a questionnaire form to identify the behavior and reaction of the respondents towards the Crime Prevention Through Environmental Design (CPTED) components is effective and sensitive. It has the ability to recognize the relationships between the various variables. The use of this scale needs continuous development to enable it to be suitable for use in any area as well as in different settings.

\section{Acknowledgements}

The researcher would like to express gratitude towards the Royal Malaysian Police Force (PDRM) for their support and cooperation in furnishing the relevant statistical data for Malaysia. The UiTM education scholarship division is also acknowledged for their sponsorship for the doctoral scheme as well as the Institute of Postgraduate Studies (IPS) in USM for the graduate research grant, which has undoubtedly assisted in the undertaking of this research. Finally, a special thanks to the respective residents of the study area for all their cooperation.

\section{References}

Aldrin, A. (1999). Crime Landscape: The Relationship of Victimisation and Fear of Crime With Residents' Territorial Functioning in High and Low Crime Rate Estate in Sheffield Department of Landscape, Faculty of Architectural Studies,. U.K, University of Sheffield.

Anastasia, L.-S. \& John, E. E. (2007). Crime Prevention and Active Living American Journal of Health Promotion, 21: 380-389.

Bennet, T., Holloway, K. \& Farrington, D. P. (2006). Does Neighborhood Watch Reduce Crime? A Systematic Review and Meta-Analysis. Journal of Experimental Criminology, 2: 437-458.

Birkbeck, C. \& Lafree, G. (1993). The Situational Analysis of Crime and Deviance. Annu. Rev. Social, 19: 113-137. 
Blakely, E. J. \& Synder, M. G. (1997). Fortress America Gated Communities in The United States, Washington D. $\mathrm{C}$, Brookings Institution Press.

Brantingham, P. L. \& Barntingham, P. J. (1993). Nodes, Paths and Edges: Considerations on The Complexity of Crime and The Physical Environment. Journal of Environmental Psychology, 13: 3-28.

Brantingham, P. L. \& Brantingham, P. J. (2005). Situational Crime Prevention as a Key Component in Embedded Crime Prevention. Canadian Journal of Criminology and Criminal Justice, 271-288.

Cozens, P. M. (2002). Sustainable Urban Development and Crime Prevention Through Environmental Design The British City. Towards an Effective Urban Environmentalism for The 21st Century. Elsevier Science Ltd., 19: 129137.

Cozens, P. M., Saville, G. \& Hillier, D. (2005). Crime Prevention Through Environmental Design (CPTED): A Review and Modern Bibliography. Property Management, 23: 328-356.

Crowe, T. D. \& Zahm, D. L. (1994). Crime Prevention Through Environmental Design. NAHB Land Development Magazine. National Association of Home Builders.

Dantzker, M. L. \& Robinson, D. M. (2002). Perspectives on Crime Prevention A Capstone View. In Robinson, D. M. (Ed.) Policing and Crime Prevention United States, Pearson Education, Inc.

De Vaus, D. A. (1986). Surveys in Social Research, London, Academic Divison of Unwin Hyman Ltd.

Devellis, R. F. (1991). Scale Development: Theory and Aplication, Thousand Oaks, CA, Sage.

Ferguson, K. M. \& Mindel, C. H. (2007). Modeling Fear of Crime in Dallas Neighborhoods: A Test of Social Capital Theory. Crime \& Delinquency, 53: 322-349.

Hafazah, A. K. \& Siti Mareenah, A. R. (2010). Community Participation: Towards a Safer Housing Environment. Asian Journal of Environment-Behaviour Studies, 1: 19-31.

Hedayati, M. M. (2009). Perception of Crime and An Assessment of Crime Prevention Through Environmental Design (CPTED) Elements in A Housing Area: A Case Study of Minden Heights in Penang. School of Housing, Building and Planning. Pulau Pinang, University Science Malaysia.

Jacobs, J. (1961). The Death and Life of Great American Cities, New York: Random House.

Lamya Rostami Tabrizi \& Ali Madanipour (2006). Crime and The City: Domestic Burglary and The Built Environment in Tehran. Habitat International, 10: 932-944

Liebermann, S. \& Kruger, T. (2004). Crime Prevention Through Environmental Design (CPTED). 9th International Conference on Crime Prevention Environmental Design Brisbane, Australia.

Minnery, J. R. \& Lim, B. (2005). Measuring Crime Prevention Through Environmental Design. Journal of Architectural and Planinng Research, 22: 330-341.

Nasar, J. L. \& Fisher, B. (1993). 'Hot Spots' of Fear and Crime: A Multi-Method Investigation. Journal of Environmental Psychology, 13: 187-206. 
Nes, A. V. and Rueb, L. (2009). Spatial Behaviour in Dutch Dwelling Area: How Housing Layouts Affects the Behaviour of Its Users. In Koch, D., Marcus, L., Steen, J. \& Stockholm (Eds.) 7th International Space Syntax Symposium. KTH.

Newman, O. (1972). Crime Prevention Through Urban Design Defensible Space, New York, The Macmillan Company.

PDRM (2008). Jenayah Indeks 2000-2007. In http://www.rmp.gov.my/\# (Ed.

Perkins, D. D., Wandersman, A., Rich, R. C. \& Taylor, R. B. (1993). The Physical Environment of Street Crime: Defensible Space, Territoriality and Incivilities. Journal of Environmental Psychology, 13.

Piaw, C. Y. (2009). Kaedah dan Statistik Penyelidikan; Statistik Penyelidikan Lanjutan Ujian Regresi, Analisis Faktor dan Analisis SEM, Malaysia, Mc Graw Hill Education.

Shu, C.-F. (2009). Spatial Configuration of Residential Area and Vulnerability of Burgalary: Case Study from UK and Taiwan. In Koch, D., Marcus, L., Steen, J. \& Stockholm (Eds.) 7th International Space Syntax Symposium.

Shu, S. C.-F. (1999). Housing Layout and Crime Vulnerability. Space Syntax Second International Symposium Brasilia.

Simons, C. F. (2002). The Evolution of Crime Prevention. In Robinson, D. M. (Ed.) Policing and Crime Prevention. United States, Pearson Education, Inc.

Sundramoorthy, P. (2008). Interpretation of Crime Index (Malaysia). Forum 'Crime and Policing in Malaysia', 2008. University Science Malaysia.

Syarmila Hany, H. (2008). The Relationship Between Territorial Functioning and Victimisation, Fear of Crime, Neighbourhood Watch and Ethnic Relations: A Case Study of Subang Jaya Housing Scheme. School of Housing, Building and Planning. Penang, Universiti Sains Malaysia.

Villarreal, A. \& Silva, B. F.A. (2006). Social Cohesion, Criminal Victimization and Perceived Risk of Crime in Brazilian Neighborhoods. Social Forces, 84: 1725-1747.

Welsh, B. C. \& Hoshi, A. (2002). Communities and Crime Prevention. Evidence-Based Crime Prevention. New York, Routledge.

Wilson, J. G. \& Kelling, G. L. (1982). Broken Windows: The Police and Neighbourhood Safety. Atlantic Monthly, March, 29-38. 